\title{
QUALITATIVE ASSESSMENT OF LINKS BETWEEN EXPOSURE TO NOISE AND AIR POLLUTION AND SOCIOECONOMIC STATUS
}

\author{
JO BARNES ${ }^{1}$, LAURA DE VITO ${ }^{1}$, ENDA HAYES ${ }^{1}$, NÚRIA BLANES GUÀRDIA ${ }^{2}$, \\ JAUME FONS ESTEVE ${ }^{2} \&$ IRENE VAN KAMP ${ }^{3}$ \\ ${ }^{1}$ University of the West of England (UWE), UK \\ ${ }^{2}$ Universitat Autònoma de Barcelona (UAB), Spain \\ ${ }^{3}$ National Institute for Public Health and the Environment (RIVM), The Netherlands
}

\begin{abstract}
The health impacts of exposure to noise and air pollution are well-documented, however socioeconomic status (SES) can be a determinant in exposure, while at the same time influencing both individual susceptibility and resilience. The scope of the work presented here was undertaken under a specific contract to the European Environment Agency (EEA) to provide an assessment that may be directly incorporated into EEA's 2018 report exploring the linkages between SES in Europe and exposure to air and noise pollution, as well as to climate-related impacts. More specifically, this research builds on the findings of the 2016 Science for Environment Policy (SEP) report (http://ec.europa.eu/scienceenvironment-policy) and provides an updated qualitative review of the latest evidence and state of knowledge regarding the role of SES in determining exposure, susceptibility and vulnerability to air pollution and noise, documenting research that explores the multiple factors and drivers that can lie behind these linkages. This review has identified and synthesised evidence from a wide range of sources in response to the objectives set by the EEA and covers evidence relating to at least 18 of the EEA-33 countries. The review has identified that there is extensive evidence on the health effects of exposure to noise and air pollution and an increasing body of evidence to suggest that effects may be disproportionately experienced, and even exacerbated by, those in lower SES groups; however, the review also highlights key knowledge gaps, and areas for future research are presented.
\end{abstract}

Keywords: air pollution, noise pollution, socioeconomic status, health, exposure, environmental justice, vulnerability, EEA, systematic review, rapid evidence review.

\section{INTRODUCTION}

The research on which this paper reports builds on the findings of the 2016 European Commission Science for Environment Policy (SEP) In-depth Report 13 [1] and provides an updated qualitative review of the latest evidence and state of knowledge regarding the role of SES in determining exposure, susceptibility and vulnerability to air pollution and noise, documenting research that explores the multiple factors and drivers that can lie behind these linkages. The SEP report recognised that there were key differentials between socioeconomic status (SES) and risk of effect from air or noise pollution, and it also highlighted that there are many inherent complexities. For example, deprived populations living in areas that are exposed to high levels of pollution, or are exposed over a long duration, may experience the worst effects, while studies to date (although limited in number) suggest that more advantaged communities are not as likely to suffer pollution-related health impacts as poorer communities, even where the advantaged communities live in more polluted areas. As the SEP report states, this potentially means that deprived populations are either more sensitive to the effects of noise and air pollution (e.g. through existing long-term health conditions, or less healthy lifestyles), or that more affluent populations are less vulnerable (e.g. through paying for better healthcare and lifestyle goods). For instance, despite living in a polluted 
area, wealthier residents may be able to afford better-constructed housing, and they may be more likely to work indoors and use private transport, avoiding negative health impacts.

The SEP report also highlighted some of the methodological challenges faced by researchers in this field, for example, different studies define SES in different ways and assess exposure and impacts at different scales. Existing research tends to focus on average exposure and impacts at the local or neighbourhood scale, but geographical units of study (i.e. the 'length size' ranging from tens of meters or kilometres) vary substantially. Overall, very few studies consider the European or global picture. The SEP report highlighted that further studies directly measuring both exposure and health impacts are needed to explore associations between SES and noise and air pollution in Europe. Longitudinal studies (involving multiple rounds of data collection) are required to understand the long-term consequences of exposure to air and noise pollution, as well as studies investigating the effects of moving between areas with different socioeconomic characteristics and with different levels of exposure to pollution.

Following the findings of the SEP report and based on the latest research, there was therefore a need to update the review based on growing evidence of the interlinkages between exposure to air pollution and noise and SES and to explore some of these complex drivers behind exposure, vulnerability and resilience, building on the recommended areas for further research highlighted in the SEP report.

\subsection{Policy context}

In the EU, air and noise pollution are regulated separately. The Ambient Air Quality Directives (2004/107/EC and 2008/50/EC) (http://eur-lex.europa.eu/LexUriServ/Lex UriServ.do?uri=OJ:L:2008:152:0001:0044:en:PDF) have set binding health-based thresholds for concentrations of various air pollutants to be met by 2015 at the latest. Many EU Member States continue to exceed limit and target values (EEA, 2017) and some are currently subject to infraction proceedings relating for instance to the nitrogen dioxide $\left(\mathrm{NO}_{2}\right)$ and $\mathrm{PM}_{10}$ limit values. The EU Clean Air Policy Package (http://www.consilium. europa.eu/en/policies/clean-air/) sets out a programme outlining measures to ensure that existing targets are met and setting out new air quality objectives for the period up to 2030, a revised National Emission Ceilings Directive (EU) 2016/2284 (http://eurlex.europa.eu/legal-content/EN/TXT/?uri=uriserv:OJ.L_.2016.344.01.0001.01.ENG\&toc= OJ:L:2016:344:TOC) , a new Medium Combustion Plants Directive (EU) 2015/21933 (http://eur-lex.europa.eu/legal-content/EN/TXT/?uri=CELEX\%3A32015L2193) and a proposal to approve amended international rules on long-range transboundary air pollution (the Gothenburg Protocol) at EU level.

The Environmental Noise Directive (END) (2002/49/EC) (http://eur-lex.europa.eu/legalcontent/EN/TXT/?uri=CELEX:32002L0049) aims to reduce the harmful effects of noise. It requires Member States to map noise levels from transport (road, rail and airports) and industry and to draw up action plans to address excessive noise pollution. The END does not set any limits or targets or prescribe specific measures to be taken but leaves these decisions to the Member States. The European Commission together with the Member States are currently discussing Annex III related to the assessment methods for harmful effects and have updated and approved the revision of Annex II related to the assessment methods for the noise indicators throughout the Commission Directive (EU) 2015/996 (http://eurlex.europa.eu/legal-content/EN/TXT/?uri=CELEX\%3A32015L0996) of 19 May 2015 establishing common noise assessment methods according to Directive 2002/49/EC of the European Parliament and of the Council. 


\subsection{Definitions of socioeconomic status}

As part of this study different approaches to defining SES, as well as how the SES of populations across Europe has evolved over the past 25 years, were reviewed. This review thereby helps to clarify some of the variability in defining SES in the literature that the SEP report identified. An extract of this review is presented in Table 1.

This review of historical and current SES proxies has revealed similarities and discrepancies throughout their evolution. As the term "socioeconomic status" suggests, its component parts are generally economic and social metrics, primarily income/poverty, employment and education. However, some sources also use social exclusion referring to a lack of access to services, discrimination and poor health. More recent examples have also introduced living environments as well, however care should be taken that metrics used as

Table 1: Review of approaches to defining socioeconomic status (SES).

\begin{tabular}{|l|l|l|}
\hline Study & Brief description & Definition of SES \\
\hline Adler et al. (1994) [2] & $\begin{array}{l}\text { Study looking at } \\
\text { the graded } \\
\text { association of SES } \\
\text { (at all levels) with } \\
\text { health }\end{array}$ & $\begin{array}{l}\text { SES is "a composite measure that typically } \\
\text { incorporates economic status, measured by } \\
\text { income; social status, measured by } \\
\text { education; and work status, measured by } \\
\text { occupation" (Dutton \& Levine, 1989, p. } \\
\text { 30) }\end{array}$ \\
\hline $\begin{array}{l}\text { Tajik and Majdzadeh (2014) } \\
\text { [3] }\end{array}$ & $\begin{array}{l}\text { Study looking at } \\
\text { constructing a } \\
\text { SES assessment to } \\
\text { address health } \\
\text { equality } \\
\text { challenges }\end{array}$ & $\begin{array}{l}\text { SES is a combined indicator for social } \\
\text { factors affecting health, which may } \\
\text { include different factors including income, } \\
\text { education, job, etc., and usually a } \\
\text { combination of them is used for measuring } \\
\text { effect of SES' }\end{array}$ \\
\hline $\begin{array}{l}\text { UK Government - } \\
\text { Department for Communities } \\
\text { and Local Government } \\
\text { Mu15) The English Index of } \\
\text { 2015 [4] Deprivation (IMD) }\end{array}$ & $\begin{array}{l}\text { Official measure } \\
\text { of relative } \\
\text { deprivation for } \\
\text { small areas in } \\
\text { England }\end{array}$ & $\begin{array}{l}\text { This SES index is based on 7 domains of } \\
\text { deprivation: income; employment; } \\
\text { education; health; crime; barriers to } \\
\text { housing and services; living environment }\end{array}$ \\
\hline $\begin{array}{l}\text { WHO. Health Impact } \\
\text { Assessment (HIA) The } \\
\text { determinants of health [5] }\end{array}$ & $\begin{array}{l}\text { Health Impact } \\
\text { Assessment }\end{array}$ & $\begin{array}{l}\text { Socioeconomic background is defined } \\
\text { based on income and social status, other } \\
\text { factors included that determine health } \\
\text { outcomes have a social and economic } \\
\text { component, such as education; } \\
\text { employment and working conditions; } \\
\text { social support networks; culture; access to } \\
\text { health services. Determinants of health } \\
\text { include also physical environment and } \\
\text { person's individual characteristics and } \\
\text { behaviours. }\end{array}$ \\
\hline Hobza et al. (2017) [6] & $\begin{array}{l}\text { Analysis of social } \\
\text { inequalities in } \\
\text { health }\end{array}$ & $\begin{array}{l}\text { "SES is defined by employment, education } \\
\text { and material wealth. People with a lower } \\
\text { SES more commonly suffer from health } \\
\text { problems such as heart disease, diabetes, } \\
\text { hypertension, and overall mortality" }\end{array}$ \\
\hline
\end{tabular}


determinants of SES are not in fact effects of SES. Hence, proxies such as the English Index of Multiple Deprivation, which comprise different "domains" can be useful for studies aiming to isolate specific determinants or to avoid autocorrelation of effect. It should be noted that SES proxies do not just vary temporally; studies undertaken in different countries will use different indices depending on available metrics.

\section{METHODOLOGY}

This paper presents some of the findings of the review undertaken to update and investigate the issues highlighted in the SEP report, reflecting the objectives outlined by the EEA. As an update to the 2016 SEP report, this review has therefore focussed on the most recent literature (primarily 2016-2018), although earlier texts have been included where relevant.

The geographical scope of the review captures a broad range of evidence from across EEA member countries, aiming to explore differences in context related to social circumstances, urban structure and environmental quality at the local, national and regional level where appropriate. The review focusses on evidence relating to ambient (outdoor) sources rather than indoor sources and is limited to evidence available as full text in English language.

The review has drawn evidence from a range of available scientific and grey literature, including policy documents and research project reports, sourced from:

- database searches of peer-reviewed papers and reports,

- requests for material from networks/contacts/projects, and

- material sourced by EEA from Eionet National Reference Centres.

The database search was undertaken in Scopus, using search terms agreed by the project team relating to:

- (Generation of/Exposure to) air pollution

- (Generation of/Exposure to) noise pollution

- Socioeconomic status (SES)

- Health impacts/vulnerability

The initial Scopus search generated 2,499 results relating to air and 730 relating to noise. Titles and abstracts were rapidly assessed for relevance to identify a "short list" of relevant papers. After deduping, a systematic review of relevant material identified 256 relevant search results relating to air and 150 for noise, covering at least 18 of the EEA-33 countries.

Requests for material were sent to 41 contacts from across Europe and further afield who had published on SES, noise and/or air pollution and health, and/or who were involved in projects relating to these topics. Responses were received from eight of the contacts providing both published and unpublished material as well as signposting project websites and current studies.

\subsection{Limitations of the review}

For evidence relating to health studies, review studies were primarily used on advice from experts at the National Institute for Public Health and Environment, Netherlands (RIVM). The breadth of relevant evidence that the Scopus search provided meant that there was no scope to expand the search to other databases. However, Scopus provides access to a wide range of relevant journals and therefore this was not considered to hamper the findings significantly. The dependence on member countries and contacts to provide additional 
evidence clearly means that this review should not be considered to be comprehensive. However, as an expert-led, systematic rapid evidence review the findings should provide a valuable contribution.

\section{DISCUSSION}

\subsection{Impacts of socioeconomic status on vulnerability to exposure to noise and air pollution}

An analysis of the evidence relating to exposure of different socioeconomic groups to noise and air pollution confirms the SEP report findings that there are multiple, sometimes interrelated, factors at play, and some inconclusive and contrary evidence to suggest that those in the lowest socioeconomic groups may not always be the most affected, depending on sources and scales of impact. In identifying the relative impacts of noise and air pollution it is worth noting that people's perceptions of traffic noise and air pollution are intertwined because they have common sources, therefore, as highlighted by Dzhambov et al. [7], simultaneously testing noise annoyance and perceived air pollution may suppress the effect of the latter, given that noise is more apparent. Furthermore, as existing evidence suggests a possible combined effect of air pollution and noise on health, primarily cognitive effects and cardiovascular effects, the established association between air pollution and life satisfaction may partly reflect the synergistic effect of noise. Further studies could control for this effect and also look at the effects of air pollution or noise on a finer temporal scale [8].

\subsubsection{Factors that help determine the exposure of different socioeconomic groups}

Understanding the metrics used to define SES is key to comparing studies which examine relative exposure. As Table 1 indicates there are many proxies for SES and studies vary depending on which metrics are available at the spatial scale under examination. Unequal distribution to air pollution exposure along the socioeconomic gradient is therefore a complex issue in European cities and no general pattern was observed to exist, but rather inequalities need to be specifically assessed in each city. It is also important to take into account both individual- and neighbourhood-level SES in order to fully describe and understand the complexity of current patterns of social inequalities relating to air pollution [9].

Generally, where people live is a major driver for disparities relating to exposure to noise and air pollution, with higher exposure found most commonly in urban areas. Urbanisation is also more specifically related to higher traffic emissions and noise, increased heat and reduced access to green spaces, which are all contributing factors. Those in lower SES groups may also have reduced accessibility to services, including public transport and may be more reliant on sustainable modes, such as walking. It was suggested in the evidence reviewed (e.g. van Wee and Ettema [10]) that the health benefits of active modes may be outweighed by additional exposure, however other studies have shown that exposure is higher within vehicles. Nevertheless, higher levels of noise and air pollution associated with location of residence has been disproportionately linked to adverse health effects in these lower SES groups.

Higher noise levels have been associated with lower housing values, which can be indicative of lower SES, although it is unclear whether house prices are devalued by their proximity to noise pollution or whether low value areas attract polluting activities, such as increased traffic. Interestingly air pollution was not observed to affect house price, presumably as the effects are less readily apparent. Alternatively, as suggested by Le Boennec and Salladarré [11], if purchasers are prepared to accept higher pollution levels as unavoidable consequences of living closer to facilities (e.g. shops), then there might be no 
reason for the price to be affected, particularly if residents can afford to adapt properties to reduce exposure, although no evidence was found to substantiate this in either this review or the SEP report.

\subsubsection{Reflections on how people on higher incomes can reduce their} exposure and increase their resilience to air pollution or noise

There is little evidence relating to the ability of more affluent individuals or households to be able to avoid air or noise pollution. Where it exists, this primarily relates to residential location as a demonstration of their ability to implement 'willingness to pay' behaviour and is most clearly apparent in relation to noise exposure [11]. As seen in the previous section, where exposure is inversely proportionate to SES, this may be as a result of the location of low-cost housing in areas subject to high levels of noise/air pollution.

This may be compounded by a higher likelihood for more polluting industries to be located in these areas and for them to be more heavily trafficked. Furthermore, the social status of these 'deprived' areas may be reinforced by more affluent householders exercising their ability to choose not to live in those locations, although it is unclear whether this is knowingly to avoid exposure. Conversely, areas with low exposure levels may also be associated with greater distance from busy roads and more greenspace, attracting wealthier residents and excluding those in lower socioeconomic groups.

\subsubsection{The role of lifestyle factors and occupation in influencing sensitivity and vulnerability}

Confounding factors relating to lifestyle are inherent in studies relating to noise and air pollution exposure in which relatively short-term (e.g. daily) temporal variations in exposure and long-term (life-course) exposure all contribute to health impacts. However, the multitude of different (indoor and outdoor) exposures and additional effects relating to lifestyle (e.g. smoking, diet) experienced within those timeframes are difficult to unpick in epidemiological studies. Within the limited evidence available, it was identified that while lifestyle may be linked to SES, lifestyle factors may be independently related to exposure and may have an additive effect in terms of health impact [12]. Studies relating to occupational risk factors are more limited, largely as by its nature this kind of exposure is generally captured by health and safety thresholds as opposed to ambient concentrations. Furthermore, we have not included studies relating to indoor air, thereby excluding the vast majority of workplace exposures. However, higher blood pressure was observed in traffic-police compared with other outdoor workers [13], cardiovascular disease mortality was associated with women in routine jobs [14], and anxieties related to job insecurity and traffic-related exposures may be likely to concur in residential and occupational contexts [15]. Ambient air pollution should therefore be a consideration for occupational exposure in outdoor occupations. Further research is required to further understand the complexity of exposure and lifestyle effects in low SES groups.

\subsubsection{Evidence of the increased sensitivity and vulnerability of sensitive population groups}

Increased exposure to air and noise pollution in low socioeconomic groups can be compounded by the susceptibility of these groups to the effects of exposure [16], a combination of factors described as the "triple jeopardy" effect [17]. Within these highly exposed, low socioeconomic groups there may also be individuals with increased sensitivity to exposure. For instance, the elderly, infants or pregnant women are more sensitive to certain pollutants [18]. This effectively adds another dimension to vulnerability, which could then 
be considered a "quadruple jeopardy" effect. Evidence indicates that children, including prenatal, the elderly and those with existing health conditions may be more represented in lower SES groups and in areas with higher exposure to noise/air pollution and are more susceptible to the resulting health impacts. However, the evidence is not unanimous.

If people in low SES groups are more likely to be exposed to environmental hazards, then their health will be even more seriously compromised. There is also some evidence to suggest that deprivation might exacerbate the effects of environmental exposure in some cases, by making those exposed more susceptible to environmental factors, perhaps because of their impaired prior health status or because of their poorer access to health care [18], [19]. The combined effects of deprivation and environmental exposure are likely to be more complex than additive.

\subsubsection{Evidence of how people of lower socioeconomic status are exposed to combined stressors}

As the earlier sections have demonstrated, living in urban areas brings a complexity of interrelated issues to bear, beyond increased exposure to air and noise pollution. People with lower SES are also subject to increased vulnerabilities and sensitivity as described in Section 3.1.4. The combination of low SES and exposure to these combined stressors is therefore of additional concern.

Generally, most of the reviewed studies demonstrate that people with lower SES tend to live in worse environmental conditions often with lower accessibility to the mitigating effects of green spaces. This is an outcome of the interaction of multiple factors. Therefore, it is highly relevant to determine the context of the analysis such as the spatial scale or the causes of inequalities. Spatial correlations between the different environmental hazards also imply that exposures will rarely occur alone; therefore, more deprived populations are likely to be subject to complex exposure mixtures.

\subsection{Impacts of socioeconomic status on generation of air pollution}

No evidence was found on the relationship between SES and generation of noise pollution, hence this section focuses purely on emerging evidence relating to air pollution generation. The premise of this section was to identify whether there was evidence that higher socioeconomic groups were contributing more to the generation of pollution to complement discussions on environmental injustice relating to exposure. Whilst there is evidence to suggest that more affluent households are net-polluters, there is also confounding evidence to indicate that the picture is less clear-cut.

Evidence from Jephcote et al. [20] identified environmental injustice in practice in Leicester, where the greatest polluters reside predominantly within affluent communities located along the cities periphery, whereas those creating the least emissions reside in central locations and experience a range of socio-environmental health burdens. Intra-urban daily commute flows were identified to be centrically focused, with private vehicle commuter journeys from affluent polluting communities passing and terminating near less affluent neighbourhoods. Similarly, Barnes and Chatterton [21] demonstrate a clear environmental injustice issue in relation to road traffic emissions in England and Wales, with areas with the lowest percentage of households in poverty having on average higher emission factors per household than areas in the highest percentile. Further analysis also reveals that those areas in the lowest percentile, i.e. high SES, own the most vehicles, including the most diesel vehicles, have on average older vehicles and drive the furthest, therefore generating the 
greatest total emissions and contributing disproportionately to traffic-related pollution [21], somewhat in contrast to Mitchell and Dorling [22] and Vanherle and Vergeer [23]. Chatterton et al. [24] also found that energy consumption varies greatly across the UK and correlates with levels of household wealth or deprivation within geographic locations, with a minority of relatively wealthy areas consuming greater amounts of energy for both car travel and domestic uses, although this may not necessarily be the case in other countries.

There is limited evidence to indicate that people in low SES may be more likely to use more sustainable modes of transport, e.g. public transport, walking or cycling; but that policies that push society to move to electric vehicles as an alternative to fossil-fuelled vehicles may be considered regressive with respect to lower SES households and more fundamental questions need to be asked about mobility needs to avoid creating further injustices relating to emissions generation [25].

Whilst the literature reviewed focused mainly on transport emissions, there is also a growing trend in wealthier urban areas to install wood-burning stoves thereby adding to particulate matter emissions among others, although this needs to be substantiated with further research. Given that these emissions will likely have a relatively localised effect and that solid-fuel burning is also a main heating source for poorer households, it is unclear whether there is a significant environmental justice issue here.

\section{SUMMARY}

This review has identified and synthesised evidence from a wide range of sources in response to the objectives set by the EEA. Links between exposure to noise and air pollution and SES are highly complex and present significant research and policy challenges. Evidence indicates that there is a relationship between exposure to both air and noise pollution and SES, largely associated with residential location in urban areas, with road traffic the major source. Other urban/environmental stressors can contribute/exacerbate health impacts in low SES groups, including lifestyle factors and occupational exposure, and vulnerable individuals within low SES groups exposed to air and noise pollution can experience increased health impacts. There is some evidence to suggest that there is an environmental injustice issue regarding emissions generation, but little evidence regarding the ability of more affluent people to avoid pollution, except with regard to choice over residential location.

This paper presents a synopsis of the review undertaken under contract to the EEA. The full report is scheduled for publication in late 2018 .

\section{KEY KNOWLEDGE GAPS AND AREAS FOR FUTURE RESEARCH}

There is extensive evidence on the health effects of exposure to air pollution and noise and an increasing body of evidence to suggest that effects may be disproportionately experienced, and even exacerbated by, those in lower SES groups. However, there are still gaps apparent in the body of research to help fully understand the interlinkages between each of the related factors. The following presents a non-exhaustive list of areas that have been identified as requiring further research.

- Emerging evidence on the health impacts of air pollution in particular need to be incorporated into this research area, especially relating to neurological effects and epigenetic effects. Added to this, a better understanding of the relative contribution of different air pollutants is necessary e.g. the additive effects of $\mathrm{NO}_{2}$ exposure;

- Investigating the interplay between air and noise (and the multiple other stressors) that affect lower SES residents of urban areas needs to be more fully understood. 
The evidence has demonstrated interrelationships between the two, but the synergistic effects are unclear. While exposure to one may be associated with exposure to the other, due to shared sources, the similarities in health impacts mean it is unclear whether their effects are additive or multiplicative. More research is therefore required to establish the extent to which any of the multiple stressors are additive or multiplicative in their effects;

- Certain exposure routes appear to be little understood. For example, more detailed exposure assessment and health risk analysis of toxic substances released by industries, e.g. urban waste water treatment plants, metal industries, mines, explosives and pyrotechnics were highlighted;

- Certain occupational exposure should also be investigated with reference to ambient air quality limits. The situation of enclosed rail stations was highlighted as potential for very high exposure for workers and members of the public, however these areas fall out of scope for ambient assessment. The relationship between personal/occupational exposure and ambient thresholds should be investigated, including also noise exposure;

- There is emerging evidence of the impact of increasing domestic solid-fuel burning in urban areas, however, further studies are required to determine the relative contribution and whether there is disproportionate exposure to the resulting emissions in areas of low SES;

- Further studies are also required to establish the link between environmental noise interventions with long-term health impacts to cover all sources of environmental noise, but particularly for aircraft and rail noise sources.

\section{ACKNOWLEDGEMENTS}

This work was commissioned and funded by the European Environment Agency (EEA) under the Framework Contract EEA/ACC/13/003/LOT-3, managed by Trinomics B.V., Rotterdam. Acknowledgements are also extended to supporting researchers, Anna Marin Puig (UAB) and Aleksandra Michalec (UWE).

\section{REFERENCES}

[1] Science for Environment Policy, Links between noise and air pollution and socioeconomic status. In-depth Report 13 produced for the European Commission, DG Environment by the Science Communication Unit, UWE, Bristol, 2016. http:// ec.europa.eu/science-environment-policy.

[2] Adler, N.E. et al., Socioeconomic status and health: The challenge of the gradient. American Psychologist, 49(1), 1994.

[3] Tajik, P. \& Majdzadeh, R., Constructing pragmatic socioeconomic status assessment tools to address health equality challenges. International Journal of Preventive Medicine, 5(1), pp. 46-51, 2014.

[4] UK Government - Department for Communities and Local Government, The English Index of Multiple Deprivation (IMD), 2015. https://www.gov.uk/government/uploads/ system/uploads/attachment_data/file/464431/English_Index_of_Multiple_Deprivatio n_2015_-_Infographic.pdf. Accessed on: 26 Jan. 2018.

[5] WHO, Health Impact Assessment (HIA) - The determinants of health. http://www.who.int/hia/evidence/doh/en/. Accessed on: 26 Jan. 2018. 
[6] Hobza, V., Hamrik, Z., Bucksh, J. \& De Clerq, B., The family affluence scale as an indicator for socioeconomic status: Validation on regional income differences in the Czech Republic. International Journal of Environmental Research and Public Health, 14(12), 2017.

[7] Dzhambov, A., Hartig, T., Markevych, I., Tilov, B. \& Dimitrova, D., Urban residential greenspace and mental health in youth: Different approaches to testing multiple pathways yield different conclusions. Environmental Research, 160, pp. 47-59, 2018.

[8] Orru, K., Orru, H., Maasikmets, M., Hendrikson, R. \& Ainsaar, M., Well-being and environmental quality: Does pollution affect life satisfaction? Quality of Life Research, 25(3), pp. 699-705, 2016.

[9] Temam, S. et al., Socioeconomic position and outdoor nitrogen dioxide $\left(\mathrm{NO}_{2}\right)$ exposure in Western Europe: A multi-city analysis. Environment International, 101, pp. 117-124, 2017.

[10] van Wee, B. \& Ettema, D., Travel behaviour and health: A conceptual model and research agenda. Journal of Transport and Health, 3(3), pp. 240-248, 2016.

[11] Le Boennec, R. \& Salladarré, F., The impact of air pollution and noise on the real estate market. The case of the 2013 European Green Capital: Nantes, France. Ecological Economics, 138, pp. 82-89, 2017.

[12] Strak, M. et al., Associations between lifestyle and air pollution exposure: Potential for confounding in large administrative data cohorts. Environmental Research, 156, pp. 364-373, 2017.

[13] Tomei, F. et al., Blood pressure in indoor and outdoor workers. Environmental Toxicology and Pharmacology, 55, pp. 127-136, 2017.

[14] Paavola, J., Health impacts of climate change and health and social inequalities in the UK. Environmental Health: A Global Access Science Source, 16, p. 113, 2017.

[15] Riedel, N. et al., Cognitive-motivational determinants of residents' civic engagement and health (inequities) in the context of noise action planning: A conceptual model. Int. J. Environ. Res. Public. Health, 14, 2017.

[16] WHO, Environmental Health inequalities in Europe. The WHO European Centre for Environment and Health, Bonn Office, WHO Regional Office for Europe, 2012.

[17] Jerrett, M. et al., A GIS - Environmental justice analysis of particulate air pollution in Hamilton, Canada. Environment and Planning A, 33(6), pp. 955-973, 2001.

[18] Marmot, M. \& Wilkinson, R.G., Social Determinants of Health, Oxford University Press: Oxford, 2006.

[19] O'Neill, M.S. et al., Health, wealth, and air pollution: advancing theory and methods. Environ. Health Perspect., 111, pp. 1861-1870, 2003.

[20] Jephcote, C., Chen, H. \& Ropkins, K., Implementation of the Polluter-Pays Principle (PPP) in local transport policy. Journal of Transport Geography, 55, pp. 58-71, 2016.

[21] Barnes, J. \& Chatterton, T., An environmental justice analysis of exposure to trafficrelated pollutants in England and Wales. WIT Transactions on Ecology and the Environment, vol. 210(12), WIT Press: Southampton and Boston, pp. 431-442, 2017. http://eprints.uwe.ac.uk/28882.

[22] Mitchell, G. \& Dorling, D., An environmental justice analysis of British air quality. Environment and Planning A, 35(5), pp. 909-929, 2003.

[23] Vanherle, K. \& Vergeer, R., Data gathering and analysis to improve the understanding of 2nd hand car and LDV markets and implications for the cost effectiveness and social equity of LDV CO2 regulations, TML/ DG Climate Action, 2016. 
[24] Chatterton, T., Anable, J., Barnes, J. \& Yeboah, G., Mapping household direct energy consumption in the United Kingdom to provide a new perspective on energy justice. Energy Research \& Social Science, 18, pp. 71-87, 2016. http://eprints.uwe.ac.uk/29047.

[25] Simcock, N. \& Mullen, C., Energy demand for everyday mobility and domestic life: Exploring the justice implications. Energy Research and Social Science, 18, pp. 1-6, 2016. 